\title{
La sonrisa de Pedro Prado
}

$\mathbf{I}$

Para todos los que llegamos a un conocimiento personal con él, el nombre de Pedro Pràdo evoca instantáneamente su sonrisa. A lo largo de cuarenta años de conocimiento, mis largas ausencias en el extranjero y sus periodos de retraimiento sólo me dejaron frecuentarlo de tarde en tarde; pero en cada una de las ocasiones que recuerdo, lo primero que apunta en mi memoria es su sonrisa. $Y$ esto desde aquella primera vez que subió a verme en el torreón de $E l$ Mercurio de Valparaíso, para darme las gracias por un elogio que yo hiciera de sus primeros poemas en prosa, hasta la última vez que lo vi en la misma calle del puerto, cuando me tomó del brazo para confirme con una sonrisa a la vez ufana y patética, que acababa justamente de sobreponerse a su tercer ataque de parálisis facial.

Aquella primera vez fué la sonrisa de un mozo de veinticinco años, de un buen mozo en todo el alcance de la palabra. Era entonces la suya esa sonrisa irrepresible de la juventud, que proviene tanto de un cuerpo sano y vigoroso como de los arrestos intelectuales de un escritor aún no bien probado por las contingencias de la vida. En Prado era más verdad que en muchos artistas de clara inteligencia aquello de "me estimo en poco mientras me examino, y en mucho cuando me comparo." Los más debían ver en esa actitud un alarde de suficiencia o de altaneria, y yo mismo quedaría por mucho tiempo con esa sospecha a causa de una objeción que puso como de paso a mi juicio sobre su librito.

- ¿ Por qué insiste en referirse a lo delicado de mi estilo? me preguntó una y otra vez. 
Pude haberle advertido a tiempo que el que "insistía" era él, puesto que yo mencionaba una sola vez en mi escrito esa palabra, que a él se le antojaba ambigua y hasta desdeñosa. (Eso que los ingleses llaman tan sagazmente "to damn a thing with small praise.") El joven Prado era orgulloso, eso saltaba a la vista, por más que procuraran disimularlo sus buenas maneras hereditarias y la finura cultivada de su espíritu. Pero se veía asimismo que entre los dones de que le había dotado tan generosamente la naturaleza, estaba la bendita y misericordiosa facultad de la ironía, contrapeso de nuestro egoísmo y solvente universal de las hinchazones de la vanidad. Así, pues, la bienhechora sonrisa destelló nuevamente, esta vez como quien dice vuelta hacia adentro, $\mathrm{y}$ su voz persuasiva y sentenciosa halló al fin la fórmula feliz de conciliación:

\section{- Quedamos en que delicado, pero no relamido, eh, Ernesto Montenegro!}

Lo veo todavía a los cuarenta años justos, con el dedo en alto, en una actitud entre admonitoria y tolerante, que su mejor sonrisa procuraba reducir a una expresión de afectuosa camaradería. Pero se advinaba que su más íntimo sentir contradecía esa determinación. Su temperamento natural era de aquellos que no admiten paridad, que aspiran en cada ocasión a ocupar el primer puesto o ninguno. En las almas bien puestas, y de preferencia en aquellas que orientan su actividad creadora hacia las artes, ese orgullo suele ser su ángel de la guarda; pero puede ser al mismo tiempo su Némesis. En su fuero interno les veremos guiarse por el código feudal del "noblesse oblige", que les manda no rebajarse nunca al empleo de las armas vulgares. Por otra parte, quien se siente un espíritu superior, no puede admitir fácilmente a sus iguales ni tener confidentes. En la intimidad de su propia familia le dolerá todavía con más punzante desasosiego el desnivel de la comprensión, tanto como la falta de una robusta y saludable beligerancia. En las relaciones sociales corrientes, el contacto obligado con la mediocridad trae a menudo el sentimiento irritante de ser víctima de una expoliación, como le pasa igualmente al viajero que al salir de una casa de cambio advierte que al trocar el dinero que le costó sus buenos sudores y fatigas, ha salido cada vez un poco estafado...

El sentimiento de superioridad innata que se transparentaba en la personalidad de Pedro Prado como a despecho de su voluntad, 
sabemos ya que tiene su sanción fatal en ese distanciamiento de todo y de todos que halla eco en sus horas de soledad, en la sorda tortura del aislamiento "esa voz que clama en el desierto." Dudo por esto que aun entre sus amigos más entrañables llegara alguna vez este hombre a sentirse enteramente a sus anchas, totalmente bien comprendido, o que se rindiera a la convicción de que alguien pudiera realmente enseñarle algo. ¿Se ha reparado, alguna vez, si no, en que éste es uno de los pocos escritores nuestros que jamás cita autores o textos, como si el afán de escarbar dentro de sí mismo no le dejase ni tiempo ni disposición para hurgar en el pensamiento ajeno? Así, en vez de imitar a Tagore como tanto snob criollo, Prado se atreve a subírsele a las barbas, inventándole un rival en ese apócrifo Karez-I-Roshan, un mito poético tan celebrado entre nosotros como aquel Ossian del profesor Macpherson lo fuera en su tiempo entre los suyos.

iAh, y qué imperativa era a veces esa sonrisa de Pedro Piado, y qué amable tiranuelo doméstico no debió ser para los de su intimidad, y precisamente por serlo!

Pero he de volver todavia a esa última entrevista en la acera de la calle Esmeralda de Valparaíso, a la puerta de un Banco de donde Prado venía saliendo en el momento en que yo pasaba, con todos mis sentidos puestos en evadir un encuentro con la panza de algún corredor de bolsa, o contra la armazón huesuda y atlética de un gringo que, echando humo como una locomotora por la chimenea de su cachimba, marcha a paso de carga entre la desbandada de los transeúntes. Ahí, frente a mí, estaba Pedro Prado con su sempiterna sonrisa. Esta era una sonrisa un poquito de través, a causa de la hemiplegia, con algo de mueca burlona y mucho de rictus neurálgico. $\mathrm{Y}$, sin embargo, quedaba no poco de desafiante y aun de triunfal en esa sonrisa. Su cara parecía la misma de antaño, siendo muy otra. Era como si yo estuviese ante un retrato de Prado jovencito, que por un descuido imperdonable hubiese quedado expuesto por mucho tiempo a los rigores de la intemperie, a los accidentes de las mudanzas del tiempo que desgasta y deslustra los más finos ma- 
teriales. La frescura rozagante del color se habia desvanecido del semblante, pero en sus ojos asomaban todavia destellos del alma juvenil.

- Van ya tres ataques, pero qué importa, repite, ilustrando su heroica jactancia con los tres dedos de una mano levantados por encima de su cabeza, como si temiera que sus palabras no fuesen bastante claras. En realidad su voz se arrastra como las piernas de un inválido, o vacila como el balbuceo del niño que comienza a soltarse a hablar. $Y$ pienso que no debió ser la menor amargura para este hombre que cuidó siempre de expresarse diảfanamente y noblemente, el verse ahora impedido de dominar como antes la conversación y mantenerla en el nivel del discurso socrático, a la vez inquisitivo, ondulante e irreductiblemente egocéntrico.

Sus amigos habían aprendido a no interrumpirle, porque siempre tenía algo interesante que decir, aun cuando no fuesen sino variaciones sobre el tema eterno del hombre en busca de sí mismo. Sabían de sobra también que a Prado cualquiera interrupción que no fuese de asentimiento le hubiese sonado a despropósito o a simple impertinencia. A sabiendas de sus íntimas limitaciones, debió pensar, sin embargo, que puesto que en definitiva jamás sabremos nada ¿a qué venía eso de acumular otros tartamudeos de ignorancia encima de lo que él había expresado ya inmejorablemente bien? (¿Qué diría el rabino al último neófito si viniese a proponerle algunas enmiendas de su mano a los textos del Pentateuco?)

Una vez, antes de lo que acabo de relatar, Prado había venido hasta mi cubil del diario, ahora en Santiago, para decirme:

- Me cuentan que usted citó en mi ausencia una anécdota mía; y querría verla. Fuimos a la biblioteca, y se inclinó por un rato sobre el grueso infolio de la colección. A propósito de la manía criolla de discursear hasta en los cementerios, había recordado yo una deliciosa salida de Prado que ponía una vez más de manifiesto esa tendencia suya a no hacer de segundón de nadie, ni dejarse tomar ventaja en cualquier terreno que fuese. Al dejar el cargo de embajador en Colombia, le of recieron el banquete de despedida que es de rigor. Le tocó presidirlo como decano del cuerpo diplomático al 
ministro inglés, y sea porque este señor fuese naturalmente contrario a las efusiones oratorias, o porque no conociera mayormente al festejado, o más probablemente por darle una lección a sus locuaces colegas, se le va ocurriendo la peregrina idea de reducir su discurso de ofrecimiento a estas dos palabras, dichas en cerrado español: "Buen viaje." Prado disimuló tolerablemente bien el desaire, si es que lo hubo, y echando mano al recurso salvador de la ironía, se dijo al instante: "Este gringo se figura que me la va a ganar a seco de palabra; pero ya verá." Y levantándose con la copa de champaña en alto, y luciendo la sonrisa más florentina de su repertorio, dijo entre la expectación de unos y la incurable malevolencia profesional de los otros, esta palabra única: "Gracias". Y volvió a sentarse sin perder la sonrisa por un instante, en la seguridad de haber dejado distanciado al laconismo británico por toda una cabeza.

Pedro Prado levantó luego la suya por entre los dos rollos de la maciza colección del diario, como quien se asoma por un portezuelo entre dos cerros, y me dijo con una sonrisa pensativa de recóndita satisfacción:

- Me ha hecho reír, pero se lo perdono. Y se llevó la mano al carrillo tirante, como para mostrarme las consecuencias de mi jugarreta.

A causa de esta conciencia innata de su propio valer, le mortificó a menudo a Pedro Prado la presencia de D'Halmar. O si alcanzó a admirarle y aun a imitarle en sus primeros ensayos en prosa, pronto llegó a la convicción de que él, Prado, calaba más hondo que el otro, por más que éste le aventajara en algunos dones físicos: la magia de una voz cadenciosa de ricas tonalidades, una presencia más imponente, la mera habilidad histriónica sobre todo. Pero al fin esas veleidades de artista se desvanecieron al sentirse más y más seguro de su posición, justamente al alcanzar ese punto del camino desde donde se abarca mejor el espacio recorrido y se ve todo en sus más justas proporciones. De esta manera pudo el hermano menor pagar en buena moneda de oro el condigno tributo al que se le adelantaba apenas en dos años a firmar la última hoja del libro de viaje de su propia vida. Es una página ejemplar, si bien no tan incondicional en su homenaje ni tan sostenida en su lírico fervor como la memorable oración fúnebre con que despidiera los restos del pintor Juan Francisco González. 
No hay mezquindad en detenerse en estas cosas. Genios incomparablemente más grandes sintieron la punzada de los celos profesionales, sin conseguir disimulárselo a sí mismos o ante los demás. Tolstoy y Dostoievsky son el ejemplo más flagrante de la literatura moderna; Voltaire y Rousseau personifican rivalidades paralelas del siglo precedente; Lope de Vega contra Cervantes empaña con su envidia el Siglo de Oro, y así podríamos seguir enumerando otros nombres ilustres entre los pintores y músicos de cada época y de cada país. En cierto modo estas prevenciones y susceptibilidades personales atestiguan lo sincero y hondo del amor a su arte que sentían todos ellos, y lo que éste representaba como justificación de los afanes de una vida entera: el anhelo desesperado de ser el primero y acaso el único en su género, o con esa expresión del orgullo imperial del romano, primus inter pares. Esa confianza en sí mismo, pese a las descorazonadoras fallas que nos revela el examen introspectivo, es tan necesaria al artista como la conciencia de tener razón contra todos. Es la misma instintiva certeza de un Walt Whitman cuando a los veinticinco años oye la reprimenda del patriarca Emerson por sus últimos experimentos de poesía panteísta. "Yo no habría sabido encontrar las palabras apropiadas para probar mi caso, escribiría mucho más tarde, ni menos podía esperar convencer a tal maestro; pero, a pesar de todo, salí con la íntima convicción de que yo también estaba en lo cierto, y que debía perseverar en mi camino."

Verdad es, por otra parte, que muchas falsas reputaciones en la literatura, como en las artes, muestran un empecinamiento todavía más terco. Pero en el hombre superior, la conciencia de ser único halla su equilibrio en su sentido de la responsabilidad. Mientras el artista sea sincero ante su propia conciencia, su obra será siempre respetable y fecunda en enseñanzas, aun cuando pierda en calidad. Una de las características de hombres como Prado es su capacidad de corregirse en todo tiempo, haciendo del propio sufrimiento una disciplina de perfección. Mientras él me decía aquella tarde que el temible tercer ataque no habia logrado hacerle mella, y me lo decía con un tono casi gozoso, yo no pude menos de recordar cierto testimonio de las luchas religiosas del tiempo de la contra-Reforma en Francia, cuando uno de esos hugonotes inçorruptibles que marchan 
al cadalso, deja oír su voz entre las lamentaciones de sus compañeros de suplicio, para animar al verdugo que lo atenazaba: " Animo, le dice, ánimo; no perdonéis sufrimiento a este miserable cuerpo!" Hallarse bien avenido con los males inevitables es ciertamente una demostración de sabiduría, tanto como de entereza de alma. Con ello probó Prado que había superado esa etapa de la literatura contemplativa y hasta cierto punto santimoniosa que Joaquín Edwards Bello llamó con su punta de sarcasmo, la de los "literatos sublimes".

Cuando se encara la obra total de Pedro Prado con ánimo de hacer su resumen crítico, tropezamos al primer intento contra la dificultad de dar con la clasificación personal que mejor cuadre a su autor. ¿Un novelista, un poeta $o$, acaso haya que endosarle ese feo calificativo de cierta actividad artística, un esteta? Hay poemas en prosa suyos, entre aquellos de su juventud, que bordean peligrosamente lo decorativo y lo rapsódico a la manera de Rodó, tal como algunos sonetos de la edad madura se pierden en el conceptismo de ciertos místicos peninsulares. En ambos casos queda la impresión de un ejercicio intelectual antes que un desahogo del alma apasionada del poeta. Aquello está bellamente expresađo casi siempre, con una cierta unción de muy buen tono, pero rara vez alcanza a conmovernos de verdad. Hay que buscar por otro lado entonces.

Repasemos sus novelas. La Reina de Rapa-Nui, la primera de las tres en su aparición, es una fantasía romántica, con algo de tour de force. Es un alarde imaginativo que va a describirnos aspectos del vivir en una isla remota, entre gentes todavía nús extrañas al temperamento del novelista - los canacas de la isla de Pascua-. La intuición poética de Prado debió sugerirle que, salvo por la decoración natural y ciertas costumbres exóticas, el hombre es el mismo en todas partes, como fué siempre el mismo desde que alcanzó la condición humana, esto es, desde que adquirió la perversa facultad de engañarse con sus propias imaginaciones y pretender con ello enmendar a la madre naturaleza. Otro escritor tan distante de la formación de Prado como los hombres anfibios de la Oceanía, el inglés Tomás Hardy, sustentaba parecidas nociones de filosofía universal: 
"La tarea del poeta y del novelista, escribió al terminar una de sus primeras obras maestras, es la de mostrar la miseria que hay en todo lo grande, así como la grandeza que hay en todo lo pequeño."

La poesía es el común denominador en esas formas de literatura que participan a la vez de lo imaginativo y lo real, tal el caso de Alsino, la novela poemática de Prado. Sea que se califique esta obra como una fábula folklórica o como una fantasía en prosa, el poeta lleva de la mano al novelista, como ocurre también con Oscar Castro y Mantiel Rojas. (Alguños críticos miopes tendrán la inclusión de este último por una extravagancia; pero es mi convicción que el tiempo justificará mi aserto, gracias a la evidencia interna que se desprende de la profunda aspiración hacia una vida mejor que flota como un espejismo aun por encima de las criaturas de más ruin apariencia en el historial novelesco del autor de Hijo de Ladrón.)

Como ha pasado siempre con las concepciones novelescas que se expresan en personajes simbólicos, son incontables las interpretaciones que se han querido dar al mito de Alsino. Hablando llanamente, la balumba de tonterías que se amontona por vía de exégesis sobre las espaldas del jorobadito, tiende más bien a oscurecer su figura y a enredar una bella historia. Los que todavía creen en la originalidad absoluta de la creación literaria, ignoran en este caso el Peter Pan de Barrie y peor aún, El maravilloso viaje de Nils Holgersson de Selma Lagerlöf, dos relatos en que un niño logra desprenderse del suelo, gracias, en el primer caso, a su resolución de seguir siendo una criatura toda la vida, y en el segundo, con recurrir al arbitrio de atraillar en su beneficio a una bandada de patos salvajes, es decir, a entregarse por entero a la naturaleza.

E1 valor original de Alsino está en mi entender en algo muy simple y muy humano a la par. Es ni más ni menos que esto: el hombre no llega a superar sus limitaciones físicas ni alcanza la plena posesión de su espíritu mientras no se libere del temor al sufrimiento, del miedo a la vida. El aprendiz de pájaro no aprenderá a volar hasta no haberse aporreado, y sus alas sólo se desanudarán cuando se encariñe con la joroba que le dejó su primera aventura. 
Vivir, esto es, la experiencia directa o intuitiva del mundo, es tan indispensable a la obra creadora como el llegar tarde o temprano a un avenimiento con la realidad. Una vez que nuestro corazón se ha fortalecido luchando cara a cara con el infortunio, cuando se ha llegado a ese pacto de conformidad con nuestro destino, entonces y solamente entonces podremos sobreponernos a las ligaduras de lo material. Desde este momento sentimos que ni los vaivenes de la fortuna ni la presión de las circunstancias pueden ya atemorizarnos realmente. Somos libres puesto que nos hemos ganado el derecho de serlo.

Léase de nuevo, a este propósito, ese perfecto poemita en prosa de Pedro Prado, "Las Pataguas", y se tendrá una buena medida de la serenidad superior que se alcanza una vez que el poeta se ha asomado a las regiones infernales y vuelve a surgir a la luz confortadora de la naturaleza, donde todos los elementos se concilian, y donde, para sentirse libre, sólo es menester someterse a la ley natural.

Pero Prado, el novelista, no alcanzará la plena reconciliación con la vida hasta no definir su filosofía personal en una obra humorística, lo más empapado de chilenidad, es decir, de humanidad que brotará jamás de su pluma, y siendo ésta su última obra mayor, resume por lo tanto el enlace de su temperamento con su experiencia de la vida. Vemos aquí a nuestro artista más puro volver a sonreír despreocupadamente, pues apenas deja atrás el retiro de su vida doméstica y sus cavilaciones sobre el misterio del ser, se encara con la ebullente realidad de la vida plebeya, vigorosa, cruda, tónica e irrepresible. Al borde de la cincuentena, y tras mucho meditar y mucho interrogarse $y$ atormentarse, he aquí al poeta ahora investido con la misión providencial de administrar justicia en un juzgado de barrio; de meter literalmente la nariz en las miserias y canallerías de la taberna y el conventillo, de las que parecía predestinado a permanecer a salvo para siempre por los privilegios del nacimiento y la fortuna. Veamos qué actitud toma Prado frente a tan fortuitos acaecimientos.

En Un Juez Rural el novelista vuelve a lucir su mejor sonrisa, la de los años mozos. Una de mis convicciones favoritas es que no sólo la vida cósmica y la historia de la humanidad se mueve en ciclos de secuencia rítmica inalterable, sino también la breve 
vida de cada uno de nosotros. Nacemos en cualquiera parte, vivimos nuestra niñez y establecemos nuestro contacto con el mundo allí mismo o en otro sitio. Lo importante no es dónde se nace, sino dónde vamos a adquirir esa primera impresión imborrable del existir, el sabor de sus frutos, la virtud de sus juegos y canciones, porque tras una larga cadena de años, que de prolongarse nos llevarán a conocer otras tierras y a otras gentes, apenas lleguen los primeros anuncios de la vejez, volveremos a sentir el tirón de esa cadena in visible que nos remachaba al pasado, y no habrá más que regresar dócilmente, si la cosa es factible, a la aldea o al pueblo donde recibimos las primeras nociones del vivir. En buena cuenta, debíamos hacer que el viejo carpintero del pueblo alargara un poco nuestra cuna para volver a acomodarnos en ella a dormir el sueño sin ensueños, volviendo así al misterio original de donde salimos.

Decía hace un momento que con esta incursión de Prado el novelista dentro de la intimidad del pueblo, vuelve a florecer su sonrisa con toda la lozanía de los primeros años. Nótese que estamos por alcanzar el tablado de la tragi-comedia. Con uma muy sugestiva regularidad alternan en esta novela los capítulos en que el autor confiesa las perplejidades de su vivir, con aquellos en que va registrando como a pesar suyo la existencia escandalosa y desaprensiva en uno de los barrios arrabaleros de Santiago, colindantes con la casa solariega del autor. Un siglo justo antes que Prado reparara en ello, el norteamericano Thoreau había apuntado en su diario: "Los hom, bres viven una vida de callada desesperación." Por cierto que muchos otros habían señalado el mismo mal en tonos ya quejumbrosos, resignados o resentidos, con Heráclito, Salomón y los filósofos del Oriente entre los primeros. Pero nos toca a cada uno de los mortales redescubrir esa verdad a nuestra propia costa, y seguir rumiándola hasta incorporarla a nuestro paladar y reconciliarnos con su sabor.

Prado le da vueltas y vueltas, recapacita con amargura, con furia, con desaliento, por turnos, en aquello de que nacimos, vivimos y hemos de morir solos, y en que nuestros pensamientos, iguial que nuestro sentir, a la par que nuestros dolores y angustias, son 
incomunicables e incompartibles. La droga salvadora está a nuestro alcance, sin embargo; basta echar una ojeada en torno nuestro para aprender a tomar menos a lo trágico nuestras aflicciones. El estoicismo del pueblo, su despreocupación por el mañana, su generosidad con otros más desvalidos, lo sufrido de su ánimo frente a las privaciones y calamidades de su existencia, reviste de contornos resignados o picarescos hasta sus peores tragedias. La malicia socarrona del pueblo comienza por desconfiar de sus propias virtudes, haciendo un comentario ćnico o despectivo de la muerte misma y reduciendo el momento supremo de rendir el alma, a esta expresión que resume todos los afanes de su vida: "Entregar la herramienta."

La moraleja de Un Juez Rural me parece igualmente instructiva. Es una lección de humildad que nos lega un gran escritor. El artista comenzó contándonos su propia historia, planeando una completa confesión en voz alta de su drama interior como la nota dominante; pero la vida desordenada del vecindario y el cinismo inocente y contagioso de la filosofía popular, vienen a sacudirlo de su ensimismamiento, dándole a aspirar como a la fuerza los zumos fuertes del suburbio, la pulla gruesa y picante del mozo diablo, la astucia instintiva del desamparado para precaverse contra las fuerzas disciplinarias de la sociedad. Y como en todo esto hierve una vida revoltosa y apasionante, que se arrebata la atención del expectador o del lector, resulta que a la vuelta de unos cuantos capítulos esta vida más intensa de la calle concluye por sobrepasarse a las divagaciones más o menos penetrantes del protagonista, del analista de almas.

Ahora si es justo y propio hacer el balance de la obra de un escritor al cerrarse apenas el libro de su vida, como es el caso presente, no creo demasiado prematuro sugerir que Un Juez Rural y Alsino han de prevalecer con el tiempo sobre su obra poética y sus poemas en prosa. Una concienzuda y experta selección de ambos me parece que serviría más a la conservación de su prestigio que la suma total de sus versos, porque la poesía pasa en nuestro tiempo por una transformación de fondo, por una verdadera revolución que envuelve una revisión de todos los valores ideales de nuestra cultura. Se está desechando lo discursivo y lo estrictamente formal, 
que tanto abunda en la poesía de Prado, por la rebusca de lo instintivo y lo subconciente, como ocurre por lo demás en todas las artes. La obra típica de Prado es más de sugerencia que de ideas, de imágenes más que de pasión. Esa sonrisa que llegó a connaturalizarse con él, el rasgo ingrávido de la ironía, lo salva del peligro de tomarse demasiado en serio y de asumir ese tono profético o la actitud oracular que ha convertido a otros escritores muy estimables en dispensadores de solemnes vaciedades.

$\mathrm{Y}$ en este punto es igualmente oportuno acaso el preguntarse qué sitio le corresponderá a éste, uno de nuestros más competentes artistas literarios, entre sus contemporáneos de habla hispana. Empapado en la conciencia de su superioridad, él se abstiene la mayor parte de su vida de frecuentar la feria intelectual. Por un breve período de su juventud se mezcla al tumulto estudiantil, haciendo característicamente de primera figura; luego es alma y sostén del grupo artístico de "Los Diez", dirige y costea una revista de este nombre junto con algunas ediciones de los autores de su cenáculo. Mucho más tarde alcanza figuración en la Sociedad de Escritores. Eso es todo. Pronto vuelve a su torre colonial, donde recibe a sus amigos, estudia y se somete a otras actividades de la industria o de su vocación de arquitecto. Pero no deja muchos testimonios de una solidaridad activa con el gremio; rara vez concurre a las reuniones sociales; nunca, que yo recuerde, comenta libros ajenos, como no sea en su correspondencia privada. Su sonrisa, trasladada a lo impreso, hubiese sido como una lima sorda en las juventudes deleznables de muchas amistades profesionales...

Tampoco le interesó mayormente Europa a Pedro Prado. La esencia de la vida europea la admiró en su arte y en la obra de sus artistas y pensadores; y lo cierto es que el mundo se está pareciendo demasiado en todas sus partes. Nuestro poeta volvió a su tierra algo desencantado y se avino de buena o mala gana a continuar el aprendizaje de su vida, para lo cual el rinconcito familiar será ya tan vasto como el cosmos, siempre que se le mire con la lente inquisidora de una inteligencia bien organizada, y que luego sirva de correctivo a la imagen aquella sonrisa con que el pequeño gigante Gulliver contemplaba a los enanitos de Liliput. 